\title{
The cognitive act and the first-person perspective: an epistemology for constructive type theory
}

\author{
Maria van der Schaar
}

Received: 16 July 2007 / Accepted: 1 December 2009 / Published online: 27 December 2009

C The Author(s) 2009. This article is published with open access at Springerlink.com

\begin{abstract}
The notion of cognitive act is of importance for an epistemology that is apt for constructive type theory, and for epistemology in general. Instead of taking knowledge attributions as the primary use of the verb 'to know' that needs to be given an account of, and understanding a first-person knowledge claim as a special case of knowledge attribution, the account of knowledge that is given here understands first-person knowledge claims as the primary use of the verb 'to know'. This means that a cognitive act is an act that counts as cognitive from a first-person point of view. The method of linguistic phenomenology is used to explain or elucidate our epistemic notions. One of the advantages of the theory is that an answer can be given to some of the problems in modern epistemology, such as the Gettier problem.
\end{abstract}

Keywords Constructive type theory - Theory of knowledge ·

Cognitive act · Judgement · Truth and error

\section{Introduction}

Current accounts of propositional knowledge (knowledge that) take knowledge attributions as their starting-point, asking what the truth-conditions are for sentences such as 'John knows that $S$ '. Such accounts of knowledge do not capture all relevant aspects of propositional knowledge, because it has an exclusive focus on knowledge as state. Knowledge as state is standardly understood as a species of the state of belief, which is taken to be a disposition or capacity to act in certain ways. Besides the notion of knowledge as state one needs to acknowledge what may be called the cognitive act.

\footnotetext{
M. van der Schaar $(\bowtie)$

Faculty of Philosophy, Leiden University, Leiden, The Netherlands

e-mail: m.v.d.schaar@let.leidenuniv.nl
} 
The cognitive act is not a special case of belief; it is an insight gaining deed, or an act of perception; it is an act, not a disposition or capacity to act. A cognitive act may be expressed by exclamations such as: 'Now I understand it', 'Now I see it', or 'Now I know it'. Although there are two types of cognitive acts, judgemental (the act of perceiving that the hawk is catching a bird) and non-judgemental (the act of perceiving the hawk), the paper focuses on the judgemental cognitive act.

Constructive type theory (CTT) may be understood as a formal system among others to which meaning can arbitrarily be given. This is not the way, though, that Per Martin-Löf understands his theory. Logic is, for him, the theory of demonstrative knowledge: "Logic studies, from an objective point of view, our pieces of knowledge as they are organized in demonstrative science, or, if you think about it from the act point of view, it studies our acts of judging, or knowing, and how they are interrelated" (Martin-Löf 1985, p. 20). On such an account, one cannot understand logic without understanding such basic concepts as judgement and knowledge. To put it in phenomenological terms: formal logic is grounded upon rational, subjective activity. Martin-Löf explains these concepts in a different way than is generally done today. One of the two aims of this paper is to elucidate these notions by means of concepts developed in linguistic philosophy by Zeno Vendler and J.L. Austin, on the one hand, and by means of the epistemic concepts that one may find in the early phenomenologists, such as Franz Brentano and Edmund Husserl. Austin once called his philosophical method linguistic phenomenology, and that term suits the method that I use here to develop an epistemology for constructive type theory. The other aim of the paper is to evaluate the epistemology presented in this paper. How can it be used to give an answer to some of the philosophical problems that we are struggling with today?

Section 2 introduces the notion of cognitive act without presupposing Per MartinLöf's interpretation of CTT. In Sect. 3 I argue that the notion of cognitive act, when used for an epistemology for CTT, is preferably understood to be a primitive notion in terms of which the other epistemic notions are to be explained. And I argue that the idea of a first-person perspective is essential to understand the notion of cognitive act. Section 4 makes a comparison between the notion of cognitive act introduced here and the account of the cognitive act given in Husserl's sixth Logical Investigation; notwithstanding the similarities, it will turn out that there is an important difference. Section 5 gives an analysis of the concepts of knowledge, judgemental correctness and evidence in terms of the cognitive act. Section 6 raises the question whether such a theory does not imply a relativism with regard to truth; the concept of error plays an important role here. Finally, Sect. 7 gives an evaluation of the cognitive notions developed in this paper by applying these notions outside the field of logic and mathematics. It is argued that these notions can be used to make sense of some of our pre-theoretical uses of the verb 'to know'. Furthermore, these cognitive notions can fruitfully be applied to some of our philosophical problems. I give an answer to the following questions: To what extent can the concept of knowledge as state be defined in terms of the cognitive act, and would this be an improvement of the explanation of knowledge in terms of belief? To what extent can the concept of fallible knowledge introduced in this paper be used to give an answer to the problem of skepticism? Presupposing that if one asserts that $S$ one claims to know that $S$, one may ask: 'What sort of knowledge is claimed in 
assertion?' And, given that the theory as it is presented here uses an internalist notion of justification: What is the answer to the Gettier problem? ${ }^{1}$

\section{Knowing as achievement versus knowledge as state}

We know because we discover, demonstrate, understand, realize, perceive, see, spot, descry or recognize. ${ }^{2}$ As Gilbert Ryle once said, such cognitive verbs signify a special type of actions: they signify achievements (Ryle 1949, p. 130). Like 'to win', to arrive' and 'to find', 'to discover', 'to perceive', and 'to demonstrate' are success or achievement verbs. And although it is now sometimes said that 'to know' is a success verb too, Ryle does not give the verb 'to know' as an example of an achievement verb. In most uses, 'to know' signifies a state or capacity, whereas the cognitive verbs just mentioned signify an action, which is characteristic of being an achievement verb. By introducing these verbs, Ryle wants us to understand that someone who has won the race or has proved a theorem has not done two things, running the race and winning it, or making certain derivations and proving the conclusion, he has done one thing with a certain upshot (Ryle 1949, p. 150).

Zeno Vendler uses Ryle's notion of achievement verb to elucidate a distinction regarding the verb 'to know'. In most cases, 'to know' is used as a state verb. There are cases, though, in which the verb 'to know' is used as an achievement verb, for example, when someone exclaims 'Now I know it!'. Later one may refer to such an achievement, and say: 'And then suddenly I knew' (Vendler 1967, p. 112). This 'insight' sense of knowing is not the same as the state sense of knowing. Knowing as insight is not related to the state of knowing as to start running is related to the activity of running, Vendler says, for knowing as insight does not start an activity. The two notions are related as getting married is related to the state of being married: knowing as insight is an achievement that initiates a state of knowing. Similarly, a flash of understanding, that is, understanding as achievement, initiates a state of understanding.

'Knowing' in the achievement sense is related to 'knowing' in the state sense as the present tense of a verb is related to its perfect form. 'Understanding' is in this way related to 'having understood', and 'seeing' that the hawk catches the bird to ' having seen' that the hawk catched the bird. It is a pity that the English language has only one verb 'to know', where most European languages have two verbs. German, for example, has the verbs '(er)kennen' and 'wissen'. 3 The verb 'wissen', which is derived from the old form wizzan (originally meaning the perfect having seen;

\footnotetext{
1 See Gettier (1963). Except for the answer to the Gettier problem, the answers to these questions are meant as first proposals. They are meant to give an idea how an epistemology for CTT can be used outside logic and mathematics. Ranta (1994) has already given extensive applications of CTT in linguistics; I have developed a semantics of linguistic mood for constructive type theory in van der Schaar (2007).

2 I leave the problem of knowledge by testimony (deferred knowledge) for another occasion. The question whether, and if so, in what sense, we can be said to know what we have learned from others will not be addressed here, either.

3 The Oxford English Dictionary, though, gives two older forms of knowledge verbs, namely 'to ken' and 'to wit', which correspond roughly to the German '(er)kennen' and 'wissen'.
} 
cf. the Duden dictionary), is used for the state of knowing; knowing as achievement is signified by the verb '(er)kennen'.

According to Vendler, achievement verbs can be predicated only for single moments of time, whereas state verbs can be predicated for shorter or longer periods of time (Vendler 1967, p. 102). The actions introduced at the beginning of this section, such as to demonstrate, to discover, and to perceive may themselves, though, be stretched out in time. An act of demonstration takes time, depending upon the number of steps that is necessary to reach the conclusion from already known premises. The achievement itself of actually reaching the conclusion after all the steps have been made, happens at a single moment of time, and we could therefore restrict the term 'act of demonstration' to this final moment, but generally we call the whole process an 'act of demonstration'. Cognitive acts, whether of demonstration, of insight, or of perception, can therefore not be distinguished from knowledge as state by saying that the act happens at a single moment of time. The distinction between the cognitive act and knowledge as state can best be understood as a special case of the distinction between an act or process and a state in the sense of a disposition to act.

The distinction between act and disposition or ability to act regarding knowledge has a long tradition, going back to Aristotle's De Anima (417a21-417b2). Apart from the capacity a human being has to become a knower, Aristotle distinguishes two meanings of the term 'being a knower'. A man may be called a knower because he has knowledge of grammar (which is a 'hexis', often translated as 'state' or 'disposition'), or he may be called a knower, because he is contemplating, that is, he "is actually and in the proper sense knowing this particular A". An act of contemplating is an actuality; it is an end (telos) in itself [cf. Metaphysica $\Theta$ (= Book IX) 1050a9-1050a10]. In contemplating, the man is exercising or actualising his knowledge as disposition (De An. 417a21-417b2). ${ }^{4}$ A man has knowledge as disposition, when: "he can if he so wishes contemplate, as long as nothing external prevents him" (idem). According to the Aristotelian order of explanation, actuality is conceptually prior to potentiality (cf. De An. 415a14-415a22), for potential means potentially actual (Metaphysica $\Theta$ 1049b13-1049b14). This principle means with respect to knowledge that knowledge as ability is fully to be explained in terms of its exercises. A man knows Greek grammar precisely means that he is able to make and understand grammatical sentences in Greek. We therefore may call him a knower of Greek grammar also when he is at the moment not exercising this ability.

Knowledge of grammar is probably not a case of propositional knowledge . It is an ability, namely the ability to apply the grammatical rules correctly. ${ }^{5}$ Did anyone apply the Aristotelian distinction between actuality and potentiality to propositional knowledge? The Aristotelian distinction was common in the Scholastic tradition. The Thomistic terminology, 'first' and 'second actuality', for, respectively, the ability

\footnotetext{
4 Hamlyn (1968, p. 23), whose translation I use, gives a clarifying note (with respect to another passage): "It is noteworthy that Aristotle believes that there is an activity of knowing, and that knowledge is not merely dispositional. In contemplating the objects of the intellect we are engaged in this activity, and it is this which the Nicomachean Ethics ultimately sets out as the end for the rational man" (Hamlyn 1968, p. 85).

5 The contrast between knowledge as ability and propositional knowledge is elucidated in Ryle (1949, Chap. II), where it is called the contrast between knowing how and knowing that.
} 
(habitus) and its exercises, is perhaps better known than the Aristotelian terminology, but Aquinas does not explicitly mention propositional knowledge in this context. John Locke is perhaps the first to apply the distinction to propositional knowledge. He introduces the distinction between actual and habitual knowledge in the fourth book of An Essay Concerning Human Understanding (1689). According to Locke, actual knowledge is an act of perception, which may be an act of insight, an act of demonstration, or an act of sensual perception. For Locke, habitual knowledge is a form of propositional knowledge. I reconstruct Locke's definition of habitual knowledge as follows, where any meaningful declarative sentence may be substituted for $S$ :

\section{P has habitual knowledge that $S$, precisely if:}

- $P$ has once had the act of perceiving that $S$;

- the perception that $S$ is stored in the memory of $P$, in such a way that: whenever $P$ thinks of the proposition that $S$, he assents to $S$, and is certain of the truth of $S .{ }^{6}$

For Locke, like for Aristotle, it is important to understand habitual knowledge as a potentiality, to be defined in terms of its actualities or exercises. Locke also adds a new point: without a first act of perception there is no habitual knowledge. The act of perception marks the beginning of knowledge as state. What Locke calls the 'act of perception', is here called the 'cognitive act'.

Concerning propositional knowledge, current analytic epistemology has exclusively focused on knowledge as state, and has neglected the cognitive act. As far as I know, only Paul K. Moser distinguishes the two forms of knowledge introduced above, and applies the distinction to propositional knowledge. ${ }^{7}$ Moser starts with distinguishing between the dispositional state of belief and the act of assent. $S$ believes that $P$-Moser uses $S$ for the speaker, and $P$ for the proposition, which is to have declarative form here-means that "(i) $S$ has assented to $P$ (consciously or unconsciously) either before $t$ or at $t$, and (ii) as a nondeviant result of his assenting $P, S$ is in a dispositional state at $t$ whereby he will assent to $P$ in any circumstance where he sincerely und understandingly answers the question whether it is the case that $P$ " (Moser 1989, p. 18). And, "One's genuinely assenting to a proposition is simply one's sincerely and understandingly affirming it" (Moser 1989, p. 15). He understands assenting and affirming in a non-epistemic sense (Moser 1989, p. 46). Such affirming, Moser says, need not be a verbal utterance or inscription, and one need not be aware of it. In dispositional knowledge one is related to the known proposition by a dispositional belief. In what Moser calls nondispositional knowledge, one is actually related to the

\footnotetext{
6 "There are several ways wherein the Mind is possessed of Truth; each of which is called Knowledge.

1. There is actual Knowledge, which is the present view the Mind has of the Agreement, or Disagreement of any of its Ideas, or the Relation they have one to another.

2. A Man is said to know any Proposition, which having been once laid before his Thoughts, he evidently perceived the Agreement, or Disagreement of the Ideas whereof it consists; and so lodg'd it in his Memory, that whenever that Proposition comes again to be reflected on, he, without doubt or hesitation, embraces the right side, assents to, and is certain of the Truth of it. This, I think, one may call habitual Knowledge" (Locke 1689, IV.i.8: 527/8).
}

7 Kevin Mulligan acknowledged the cognitive act, both in its propositional and in its nominal sense (the act of seeing the hawk), in a lecture held at Leiden, December 2006. The next note shows that Franz von Kutschera also makes the relevant distinction. 
known proposition not by a dispositional belief, but by genuine assent (Moser 1989, p. 21); nondispositional knowledge is not a species of belief, but a species of assent. Moser explains dispositional knowledge as true justified belief, and nondispositional knowledge as true justified act of assent. Nondispositional knowledge standardly results in dispositional knowledge, but it may also be merely transitory, perhaps because of some defect in the knower's memory system, as is the case in Moser's Mr. Lawless, who can affirm $P$, but who cannot obtain any disposition to affirm $P$. According to Moser, Mr. Lawless may be said to 'know' in the transitory, nondispositional sense, although he cannot have dispositional knowledge. Although Moser does not use the term 'cognitive act', what he calls 'the true justified act of assent' is an example of a cognitive act.

Conceptually, there are three ways to relate the concepts cognitive act and knowledge as state. First, one may explain both the cognitive act and knowledge as state in terms of more primitive notions, as Moser has done. Second, the cognitive act may be explained in terms of knowledge as state: the cognitive act is characterized as a coming or getting to know, that is, the cognitive act is explained as the act or process through which one comes or gets into a state of knowledge. ${ }^{8}$ The third way to relate the two notions is by explaining knowledge as state in terms of the cognitive act, as Locke for example has done. If one relates the notions of cognitive act and knowledge as state in this third way, the notion of cognitive act is given the most prominent place.

In this paper, I argue that the cognitive act is of importance for an epistemology that suits constructive type theory, and for epistemology in general. Because knowledge as state is a disposition, it needs to be explained in terms of its actualisations, that is, in terms of the cognitive act. If one asserts in a dialogue situation '(I know that) S', an interlocutor is entitled to ask 'How do you know that?', that is, one has to be able to give an account of the way one has obtained one's knowledge state. One obtains a state of knowledge by means of an act of demonstration, an act of discovery, an act of understanding, an act of perceiving, or an act of recognizing; these are some of the sorts of cognitive act that may result in knowledge. Below I argue that the cognitive act is preferably not to be explained as (1) an act of judgement, (2) that is justified and (3) right. I take the notion to be primitive. Although it is thus not possible to define the notion of cognitive act, it is possible to elucidate the notion by giving examples, as I have done already above, and by showing how the notion is related to other notions, which will be done below.

In this paper, the notion of belief does not form part of the explanation of knowledge. A dispositional notion such as belief cannot be understood as primitive, because we

\footnotetext{
${ }^{8}$ Franz von Kutschera (1981, p. 9) gives an explanation of cognizing (erkennen) in terms of knowledge as state (wissen): "Die Person a erkennt, im Zeitpunkt t, dass p, genau dann, wenn a in t von einen Zustand des Nichtwissens, dass $\mathrm{p}$, in einen Zustand des Wissens, dass p übergeht." From this definition he draws the conclusion that an analysis of the concept of knowledge as state, being the more primitive notion, suffices for epistemology. In contrast, defining knowledge as state in terms of cognizing (the act of cognition) brings the act of cognition into focus.
} 
need to explain a disposition in terms of its actualisations. Besides, the term 'belief' is an ambiguous notion, which may mean: a disposition or ability to judge; (a certain degree of) conviction; or faith. One should not explain knowledge in terms of 'belief', as long as it is not clear what is understood by that term. ${ }^{9}$ Below, knowledge (as state) is not explained in terms of belief, but in terms of the cognitive act. Because knowledge and the cognitive act are not explained in terms of belief and the act of judgement, the conceptual order of these notions is essentially different from the order in modern analytic philosophy, and another method is needed to explain the relation between these notions. This method I call linguistic phenomenology, and modification and etiolation of meaning play a certain role in it, which ideas will be explained below.

\section{The cognitive act and the first-person perspective}

In the explanation of the epistemic notions that are essential to understanding Per Martin-Löf's interpretation of constructive type theory, the notion of cognitive act, or act of knowing, plays a central role. How the notion of cognitive act is to be understood is not unproblematic, though. I understand the notion of cognitive act to be identical with the notion of justified or grounded judging, but I do not explain the notion in terms of the act of judging and being grounded.

A cognitive act may be an act of demonstration or an act of (immediate) insight. The act of demonstration is an act of judgement based upon known premises; this act of judgement is therefore a cognitive act. An act of insight is an act of understanding, for example, that 0 is a natural number. One sees that 0 is a natural number as soon as one understands that 0 is a natural number. One cannot make the judgement without understanding the concepts involved, and thereby knowing that 0 is a natural number.

The cognitive act plays an important role in the epistemology that is developed here for constructive type theory, because other epistemic notions are explained in terms of it. The cognitive act is prior in the order of explanation to, for example, the concept of knowledge as state. Science does not consist in a unified whole of cognitive acts, but in a whole of pieces of knowledge or of knowledge states in the individual scientist. Pieces of knowledge are, for Martin-Löf, the product of an act of knowing. One may thus apply the traditional distinction between act or process and product to the concept of knowledge ${ }^{10}$ : the act of knowing or the cognitive act results in knowledge as product. ${ }^{11}$ How is this relation between cognitive act and knowledge as product to

\footnotetext{
9 I criticize the way the term 'belief' is used in modern epistemology in van der Schaar (2009).

10 The distinction between act and product is acknowledged in the scholastic tradition, especially the Thomistic one. In Aquinas the product is called the terminus (ad quem). The terminus of an act of knowing, the 'inner word', the known proposition (in the old-fashioned sense, having declarative form), is distinguished from the external object of knowledge. More on the distinction between act and product in van der Schaar (2006).

11 The German term is '(eine) Erkenntnis', which is preferably translated as '(a) cognition', as is done by Werner S. Pluhar in his translation of Kant's Kritik der reinen Vernunft from 1996. Because Martin-Löf does not use the term '(a) cognition,' but the term 'knowledge' for the product of the act of cognition, I conform to that usage; cf. Martin-Löf (1985, pp. 19, 20).
} 
be understood? The relation between the act of cognition and knowledge as product is not a natural, causal relation; it is an internal relation: knowledge as product is inevitably constituted in a cognitive act. Knowledge as product, a piece of knowledge, is an abstract entity, and has as such an enduring existence from the moment on that it is made in the cognitive act. Theorems are typical examples of knowledge products. Knowledge as product, being an abstract entity, is not to be identified with the knowledge state of an individual knower.

Regarding knowledge as state, Martin-Löf makes the following equation: "to know = to have understood, comprehended, grasped, seen" (Martin-Löf 1985, p. 20). The act of understanding is an example of a cognitive act resulting in (knowledge of) an axiom. Knowledge as state can thus also be understood in terms of the cognitive act. The cognitive act that inevitably results in knowledge as product, may also result in a knowledge state of the individual knower. The relation between the cognitive act and knowledge as state is not an internal one. As the example of Mr. Lawless has shown (see the introduction), there may be exceptions to the rule that the cognitive act results in knowledge as state. A man's cognitive act standardly initiates in him knowledge as state, but there may be physical or psychic hindrances. The relation between cognitive act and knowledge as product is thus tighter than the relation between cognitive act and knowledge as state.

One may either explain the notion of cognitive act by means of the notion of judgemental act together with the notion of justification and perhaps a truth notion, or the notion may be understood as primitive in the sense that it cannot be explained in terms that are prior in the order of explanation, and the act of judgement is then understood as being, in a certain sense, identical with the cognitive act. Martin-Löf has understood the notion of cognitive act to be primitive in his earlier writings, but he has now changed his position: the act of knowing is explained as justified, or grounded, judging, and the act of judgement is identified with the act of assertion. ${ }^{12}$ The notion of truth is missing in the explanation of cognitive act, because being justified implies being correct, where correctness is epistemic correctness (see Sect. 5). The identification of judgemental act and cognitive act is not unproblematic, as we will see below, but the identification of act of judgement and act of assertion creates problems of its own, for when we lie we make an assertion without the corresponding judgement. I argue here for the identification of judgemental act and cognitive act, because this way of relating the two notions shows something important about the constructive notion of knowledge.

Below I understand a mere act of judgement as a modification of a cognitive act. ${ }^{13}$ To understand what modification is, it is important to understand what modifying adjectives are, such as 'fake', 'mock', or 'sham'. If an attributive (non-modifying) adjective precedes a general term in a singular, atomic sentence, one may validly draw the conclusion that the subject falls under (the concept denoted by) the general term. From the assertion 'He has a German pistol,' in which 'German' is used

\footnotetext{
12 As he writes to me in a letter from 17 August 2007. His early identification of act of judging and act of knowing can be found in Martin-Löf (1985, p. 19, 1991, p. 144); cf. also Sundholm (1998, p. 183).

13 Compare Husserl in Erfahrung und Urteil: "blosses Urteilen [ist] eine intentionale Modifikation von erkennendem Urteilen" (Husserl, 1939, Sect. 5, p. 15).
} 
attributively, one may validly draw the conclusion 'He has a pistol.' If a modifying adjective precedes a general term, as does the term 'sham' in the assertion 'He has a sham pistol,' one cannot validly draw the conclusion that he has a pistol.

One may have doubts regarding the identification of the judgemental act with the cognitive act, for it seems that there is no conceptual space for error on this account. After all, some of our judgemental acts will turn out to be unjustified and incorrect, and such an act of judgement cannot be identified with a cognitive act, that is, an act of knowing. There are cases in which we are not entitled to judge, while making the judgement nonetheless. I do think, though, that one can give an account of error, even though the cognitive act is understood as primitive, and the judgemental act is, in a certain sense, identified with the cognitive act. In what follows I presuppose that there is a distinction between making a guess and making a judgement: without having a justification or ground, one does not judge, one is merely making a guess. This means that for someone to count as a judger he needs to have a ground for the judgement he is making. (Below I will explain the point that the ground is to be understood as what counts as a ground from a first-person perspective.) Prima facie, the act of judgement is grounded, and is in this sense a cognitive act. Later, it may turn out that there was something wrong with the ground, and the act of judgement is considered to be a misfire, because something essential is missing. As soon as the judger realizes that his 'ground' can no longer be considered as ground, he withdraws his judgement. Now that he considers what he used to call a 'ground' no longer to be a ground, he may still say that he made a judgement in the past, but then the term 'judgement' is used in a modified sense (a full account of error is given in Sect. 6). The concept of judging without a ground is thus secondary in the order of explanation to the notion of grounded judging, and the latter is precisely identical with the primitive notion of cognitive act. The cognitive act may thus be understood as the primitive notion, and mere judgement (without a ground) is a notion that can be understood as a modification of the cognitive act.

Perhaps this sounds like Henry VIII's denial that there has been a marriage, notwithstanding the fact he and his first wife went through all the procedures, simply because it didn't bring him the right kind of offspring. I do think, though, that the point is important for understanding what epistemic concepts one needs for constructive type theory. Primary cases on the basis of which the concept of knowledge is explained on this account are not knowledge attributions, but first-person knowledge claims. And from a first-person perspective, there is no distinction between the act of judgement and the cognitive act, the grounded act of judgement. I understand my judgement to be grounded; it is not merely a guess. I understand it to have epistemic value, and this is so, because I take it to be grounded. ${ }^{14}$ The cognitive act is thus prima facie cognitive, or cognitive from a first-person point of view. Only someone else (or the same judger at another time), with his own first-person perspective, who evaluates the epistemic situation, may come to the conclusion that the act of judgement of the person introduced above is not grounded, and that it is therefore not a

14 A similar thesis I found in Adler (2002, p. 275): "From the first-person point of view, one treats one's belief as factive, which is the central property of knowledge". Throughout Belief's Own Ethics, Adler stresses the importance of a first-person methodology. 
cognitive act. The notions of cognitive act and act of judgement may fall apart. If I see that the ground on the basis of which you make your judgement is defective, I am entitled to say, given my first-person perspective, that your act of judgement is not a cognitive act. The idea that the cognitive act counts as cognitive from a first-person perspective, has far-reaching consequences. It means that a ground or justification is always a ground or justification from a first-person perspective, and because (epistemic) truth will be explained in terms of justification (see Sect. 5), 'being (epistemically) true' means 'being true-for-me'. This means that knowledge is understood as inherently fallible, and that there is a threat of relativism, which problem is addressed in Sect. 6.

Not all judgemental acts seem to be equally cognitive. Some create a knowledge product, others do not, but initiate a new knowledge state in the person making the act. Finally, we sometimes merely bring to the occasion, for ourselves or aloud, a knowledge already obtained. There seems to be a difference between a first cognitive act that $S$ that results in the abstract knowledge product $S$, and standardly initiates a corresponding state of knowledge, on the one hand, and subsequent acts of judging that $S$, on the other hand. These subsequent judgemental acts are the exercises or actualisations of knowledge as state or disposition. Although these repeated judgemental acts are still cognitive, in so far as they are exercises of dispositional knowledge, they are not full cognitive acts in the sense that they create a knowledge product or initiate a state of knowledge. As cognitive acts, these repeated judgemental acts are 'etiolated', to borrow a term from J.L. Austin. The term 'etiolated' before a term, diminishes the meaning of that term without changing the meaning in an essential way. An etiolated cognitive act is still a cognitive act. The concept of etiolation is not the same as that of modification introduced above. Both etiolation and modification involve a change in meaning, a kind of diminishing, but only in the case of modification the change is essential: when 'stage' works as a modifying term, a stage tree is not a tree, whereas an etiolated plant is still a plant. With respect to the cognitive act, there are two kinds of etiolation. The cognitive act may be etiolated because it does not result in a new knowledge product. Because the knowledge product already exists, the act is not original, but the act may still initiate a new knowledge state in the individual knower. Or, the cognitive act is etiolated in the full sense: it neither creates a new knowledge product, nor does it initiate a new knowledge state. It may still be called cognitive because the judgemental act is an exercise or actualisation of dispositional knowledge.

The cognitive act is of importance for constructivism, for only when constructed in a cognitive act do proofs for propositions gain epistemic significance. Propositions are considered to be sets of their proof objects, but their meaning-explanation is given exclusively in terms of their canonical proof objects. ${ }^{15}$ Two questions are of importance in the explanation of a proposition: How are its canonical proofs formed? And, when are two such proofs equal? A non-canonical proof object for a proposition is a method which yields, when executed, a canonical proof object for that proposition (Martin-Löf 1998, p. 112). A proposition is true precisely if

15 On the relevance of the distinction between canonical and non-canonical proof object for CTT, cf. van der Schaar (2007). 
a proof of it exists. That is, on the presupposition that $A$ is a proposition, the judgement

$A$ is true

can be identified with the judgement

there exists a proof of $A$, i.e., Proof $(A)$ exists. ${ }^{16}$

The term 'proof' here means proof object. ${ }^{17}$ The idea that proofs of propositions are objects also finds expression in the thesis that these objects are the truth-makers for the relevant propositions. ${ }^{18}$ What is relevant here is that a proof object is an (abstract) object, not to be confused with the cognitive act, such as an act of demonstration. A proof object is an object to be denoted by a singular term. For example, a canonical proof object for a conjunction $A \& B$ is a pair of proof objects, the first being a proof of $A$, the second being a proof of $B$. A canonical proof object of an implicational proposition $A \supset B$ has the form of a $\lambda$-abstract: $(\lambda x) b(x)$, where $b(x): B(x: A)$, that is, where $b(x)$ is a proof object of $B$, given that $x$ is a proof object of $A$. These proof objects as such are non-epistemic objects.

It is essential to constructivism that the person who asserts that there exists a proof of $A$ is entitled to make that assertion only if he is entitled to make the assertion

a is a proof of $A$.

He is allowed to make the existential claim only upon possessing a proof for $A$ (cf. Sundholm 2004, p. 449): existence is thus understood in the constructive sense. This means that the person who asserts that $A$ is true is entitled to make that assertion only if he has constructed a proof object for $A$ within a cognitive act, such as an act of demonstration. It is only in this way that proof objects gain epistemic significance. In order to obtain constructivism, the semantic talk in terms of propositions and proof objects needs to be embedded within a theory of the cognitive act, in which proof objects are constructed as proofs of their propositions. This point has both a meaningtheoretical aspect and an epistemic aspect, and it is the latter aspect that is dealt with in this paper. ${ }^{19}$

Although the constructive notion of knowledge may seem to be subjective because it is the result of a cognitive act that counts as cognitive from a first-person point of view, one cannot privately decide what counts as a proof for a certain proposition. The semantic notion of a proposition $A$, which is part of the judgement $A$ is true, is

\footnotetext{
16 The notion of existence that is used in this judgemental form has to be different from the notion of existential quantifier that is present in existential propositions.

17 Arend Heyting has introduced the idea to explain propositions in terms of proofs, and this has led to the idea that proofs for proposition are non-epistemic, mathematical objects, or proof objects. Cf. Sundholm (1994, p. 121).

18 Cf. (Sundholm, 2004, p. 438). The notion of truth for propositions can be explained in terms of truthmakers: the above 'there exists a proof of A' is then substituted by 'there exists a truth-maker for A', cf. (Sundholm, 1997, p. 117).

19 That a semantics in terms of propositions and proof objects needs to be embedded within a meaning theory of assertion conditions given in epistemic terms is shown in van der Schaar (2007).
} 
explained in non-mentalist, public terms. As we have seen, the proposition $A \& B$ is explained by what its canonical proof objects are, pairs consisting of a proof object of $A$ and a proof object of $B$. Equally, what counts as a non-canonical proof object for a proposition is determined independently of any judger's act. Only the point whether there exists a proof object for the relevant proposition is dependent upon a first-person cognitive act, in which that proof object is to be constructed.

\section{The cognitive act and the phenomenological account of knowledge}

In the former section, I introduced a methodology in which the ideas of modification and etiolation play a role in the explanation of the notions of cognitive act and act of judging. The terminology I took from Husserl and Austin, and I have introduced an explanation of the idea of modification and etiolation in logical and linguistic terms, thus introducing a new method to explain or eludicate our epistemic concepts. Regarding the concept of cognitive act as I have introduced it, there is also a close relation between constructive type theory and phenomenology. The notion of cognitive act can be elucidated by making a comparison with the elucidation Husserl has given of the cognitive act (das Erkennen) in the sixth Logical Investigation. According to Husserl, there are three moments involved in the cognitive act ${ }^{20}$ :

(1) the act of empty meaning intention;

(2) the act of intuition or perception, which is to function as the fulfilling act in (3);

(3) the cognitive act, which is a single act that brings the former two acts into synthesis, in such a way that the act of perception fulfils the act of intention (only at this moment the second act is understood as a fulfilling act).

In the case of cognizing (Erkennen) non-propositional objects, the fulfilling act is an act of sensual intuition, and the act of synthesis is a cognitive act in which the object intuited in the second act is identified with the object meant in the first act. Instead of an act of identification, the cognitive act may also be an act of classification, for example, when the object perceived in the second act is classified as inkpot, which meaning was intended in the first act; the object is thus cognized as inkpot (Husserl 1901, VI, Sect. 6). In a further cognitive act, the object may then be identified as my inkpot. The cognitive act thus brings the act of intention and the act of perception, the fulfilling act, into synthesis. The act of intuition or perception as such, without an act of cognitive interest, is epistemically irrelevant. The same perception can fulfil different meaning intentions, such as inkpot and my inkpot, and without such a meaning intention, there is no concept under which the perceived object can be taken, which means that the act of perception has no cognitive value. It is not the word, or its meaning, and the object that are primarily related to each other in the synthesising act, but the act of meaning

\footnotetext{
20 Cf. Husserl (1901, VI, Sects. 6 and 8). "Eben darum dürfen wir nicht bloss die Signifikation [first act] und Intuition [second act], sondern auch die Adäquation, d. i. die Erfüllungseinheit, als einen Akt bezeichnen, weil sie ein ihr eigentümliches intentionales Korrelat hat, ein Gegenständliches, worauf sie 'gerichtet' ist. Wieder eine andere Wendung derselben Sachlage ist, nach dem oben Gesagten, in der Rede vom Erkennen ausgedrückt” (idem, VI, Sect. 8, p. 568). Compare Husserl (1901, p. 1901, VI, Sects. 38 and 40).
} 
intention and the act in which the object is perceived. The cognitive act is a primitive phenomenological fact, and is not to be reduced to the mere sum of the other two acts; consciousness that the one act fulfils the other is essential to the cognitive act. ${ }^{21}$

In the case of judgemental cognition (Husserl 1901, VI, Sect. $38 \mathrm{ff}$.), the act of empty meaning intention (1) is, for example, an act of wanting to know whether the bird in the garden is a robin. The act of perception is (2) an act of non-sensory perception of an ideal entity, the state of affairs the bird in the garden being a robin. Finally, (3) there is a cognitive act that the bird in the garden is a robin, if and only if the perception of the state of affairs is apprehended as fulfilling the act of empty meaning intention. If the fulfilment is complete, the cognitive act is evident in the strict sense, and its correlate is (judgemental) truth. ${ }^{22}$

In the sixth Logical Investigation, judgemental truth is thus elucidated by means of evidence, and ultimately by means of the distinction between intention and fulfilment. Besides judgemental truth, Husserl acknowledges propositional truth, which he understands as truth pertaining to states of affairs (the bird's being a robin/ that the bird is a robin), consisting in the correspondence of what is meant (a meaning intention not as act, but as content of an act) and what is given [fulfilment not as act, but as content of a (fulfilling) act] (cf. Husserl 1901, VI, Sects. 37 and 38; this is 'the first concept of truth'). If one understands Husserl's position in the sixth Logical Investigation in idealistic terms, truth pertaining to states of affairs cannot be understood without the evident cognitive act with its fulfilling synthesis, in which the truth of the intended state of affairs is determined. There is only truth in the sense of correspondence in so far as there is a fulfilling synthesis of subjective acts. ${ }^{23}$ Although Husserl considers the cognitive act to be a primitive phenomenological fact, it is possible to elucidate the notion of cognitive act.

In order to compare the concept of cognitive act as introduced in this paper with the phenomenological concept of knowledge, a distinction between proposition and judgement candidate needs to be made. ${ }^{24} \mathrm{~A}$ proposition $A$, which was introduced above as a set of proof objects, has the form of a that clause; the judgement candidate of the judgement $\vdash A$ is true, where $\vdash$ is a sign of judgemental force, has the form $A$ is true. A judgement may thus be understood as a judgement candidate to which judgemental force is added. The proposition as such, having the form of a that clause, does not have the right form to be judged or asserted. According to Martin-Löf, what a judgement is, "is fixed by laying down what it is that you must know in order to have the right to make the judgement in question" (Martin-Löf 1995, p. 188). The term 'judgement' is ambiguous: it may mean the judgement candidate together with

\footnotetext{
21 "Es ist eine primitive phänomenologische Tatsache, dass Akte der Signifikation und Intuition in dieses eigenartige Verhältnis treten können" (Husserl 1901, VI, Sect. 8, p. 567).

22 "Urteil [first act] und Urteilsintuition [second act] einen sich dabei zur Einheit des evidenten Urteils" (idem, VI, Sect. 44, p. 668). Cf. (idem, VI, Sects. 38 and 39).

23 Cf. Bernet et al. (1989, Chap. 6, esp. p. 174). According to Tugendhat, this idea can only be found in Husserl's Ideen, published in 1913, cf. Tugendhat (1970, pp. 89, 90). The first edition of the sixth Logical Investigation, though, forms already a transition to Husserl's idealism.

24 I have argued for the importance of the judgement candidate in van der Schaar (2007), where it is called the 'assertion-candidate'.
} 
the judgemental force, or it may mean the judgement candidate as such, and it is the latter sense that is captured by the definition. A presupposition for putting forward the judgement candidate with assertive or judgemental force is that one understands the judgement candidate, that is, that one understands what one must know in order to have the right to make the judgement in question. It is essential to the judgement candidate that one can apprehend it without making the judgement oneself. Before one has constructed a proof object for $A$ and judges/cognizes that $A$ is true, one needs to apprehend the judgement candidate $A$ is true, that is, one has to understand what proof object has to be constructed to make $A$ true. The act of apprehending the judgement candidate and the act of cognition may happen at the same moment, but it is important to understand that they are conceptually different; one can have the former without the latter.

There is an important difference between the notion of cognitive act as part of an epistemology for constructive type theory and Husserl's notion of cognitive act. Within constructive type theory all objects come as typed. One cannot conceive of an act in which a proof object is found independently of the proposition for which it is a proof; there is an internal relation between proof object and proposition. Because all objects belong to a certain type, proof objects are not found or constructed independently of the question for what proposition they are a proof. The act of finding a proof-object is essentially an act in which a proof-object is found for the relevant proposition. For Husserl, the same act of intuition or perception may fulfil different intentions, for example, there is a bird, the bird flies away, or the black bird flies away. Thus, in Husserl, a separate act is needed to understand the act of perception as fulfilment of a certain intention: the cognitive, synthesising act. In an epistemology for CTT, one need not make a distinction between the act of intuition or perception and the cognitive act. The act in which a proof object is constructed for the relevant proposition, is precisely the cognitive act.

The phenomenological threefold distinction thus becomes a twofold distinction in an epistemology for constructive type theory:

(1) the act of apprehending the judgement candidate, such as $A$ is true;

(2) the act of cognition, in which a proof-object $a$ (the fulfilment as object) for the proposition $A$ (the intention as object) is constructed. ${ }^{25}$

The act described in (1) is needed, because we have to understand what we must know in order to have the right to make the judgement. The act in (2) can be understood as the fulfilment of the act in (1). One may also think of intention and fulfilment in terms of objects, as indicated in (2), but it is essential to constructivism that the distinction between intention as object and fulfilment as object is embedded in the distinction given in terms of acts, as in (1) and (2).

Apart from the difference between Husserl's and the constructivist's account of the cognitive act given in this paper, there are also some important agreements. The cognitive act is understood as a primitive phenomenon, not to be explained in terms

\footnotetext{
25 Heyting already used the Husserlian distinction between intention and fulfilment for the explanation of intuitionistic ideas: "Die Behauptung einer Aussage bedeutet die Erfüllung der Intention" (Heyting 1931, p. 113).
} 
of truth, justification and belief. How knowledge is related to truth and justification on a constructivist account will be explained in the next section.

\section{Knowledge, evidence and judgemental correctness}

Above, knowledge as product is defined as the internal result of the cognitive act, but Martin-Löf also elucidates the notion of knowledge as justified or evident judgement (Martin-Löf 1998, p. 110). A judgement candidate is made evident by an act of demonstration (Martin-Löf 1987, p. 417, 1998, p. 108), or an act of insight. A judgement made evident by a cognitive act can be considered both as knowledge in the sense of knowledge product and in the sense of knowledge as state. That a judgement is evident means that it is known, and it can be made known only through a cognitive act. Whether a judgement counts as knowledge is thus dependent upon the cognitive act of a judging agent. If the act of cognizing is not based on other judgements, that is, if the act is an act of insight, the judgement is traditionally called immediately evident, and the evident judgement is an axiom. If the act of cognition is based on other evident judgements, that is, if the act is a demonstration, the judgement is called mediately evident (Martin-Löf 1985, p. 30), and the evident judgement is a theorem. ${ }^{26}$

One may wonder whether there is a circle in the explanatory order of the notions knowledge and judgement: knowledge is characterized as justified judgement, and judgement in the sense of judgement candidate is defined in terms of what one has to know in order to be entitled to make the judgement. There is an important difference, though, in the meaning of the term 'knowledge' and that of the term 'to know' as it is used in the two explanations. When knowledge is characterized as justified judgement, it is knowledge as product that is explained. When the term 'to know' is used to define the judgement candidate, it is the cognitive act that is indicated. The judgement is defined by what one has to do in order to have the right to make it, and the act that one needs to have done in order to be entitled to make the judgement, is the cognitive act. If one puts the two explanations together, one obtains: knowledge as product is the judgement candidate justified by the cognitive act that is demanded by the explanation of the judgement candidate in order to be entitled to make it; in short, knowledge as product is the result of the cognitive act.

A judgement is called correct, if it is possible to make it evident or justified, that is, if it is knowable (cf. Martin-Löf 1998, p. 109). After one has justified the judgement, one is entitled to assert that the judgement candidate that one had apprehended before the judgement was made evident, is correct. The judgement candidate is thus the bearer of correctness. The notion of correctness cannot be understood independently of the notion of being evident, because the two are related as potentiality to actuality: the former notion has to be explained in terms of the latter. Given this meaning of correctness, explaining knowledge as justified correct judgement, or 'justified true belief' in the standard formulation, is less apt, because the notion of being correct is here

\footnotetext{
26 Current epistemology uses the term 'evidence' primarily in the sense of evidence for a judgement. The evidence for a judgement that $S$ consists of those judgements that justify the judgement that $S$. If one uses evidence in this sense, there is no evidence for an axiom. According to the use of the term 'evident' introduced here, where being evident is a characteristic of certain judgements, an axiom is an evident judgement.
} 
redundant: the judgement's being evident or justified implies its being correct. The evidence of a judgement is not only a criterion for its correctness; the notion of evidence is part of the definition of judgemental correctness. Here, as in Husserl, judgemental correctness is not the same as truth of a proposition. The explanation of propositional truth in terms of 'existence of a proof of $A$ ' can be understood in a non-epistemic sense, whereas the notion of judgemental correctness is defined in epistemic terms.

A judgement's being evident has two aspects. On the one hand, the judgement is justified, grounded by a cognitive act. In this sense, axioms are also justified, namely by an act of insight. On the other hand, the judger is convinced of the correctness of the judgement. A judgement's being evident is a subjective characteristic; a judgement is evident to a certain person. Being evident is not a purely subjective characteristic, though. The judger should be convinced of the correctness of the judgement because of the cognitive act. Strong conviction of the correctness of a judgement without the cognitive act to support this conviction is not to be identified with the evidence of the judgement. Conviction or sureness without the corresponding cognitive act is nothing but a feeling that may equally accompany our prejudices. Evidence is not a mere feeling.

Under the influence of the criticism on the concept of evidence by the logical positivist Moritz Schlick (Allgemeine Erkenntnislehre, 1918) and the Neo-Kantian Leonard Nelson, the notion of a judgement's being evident, the evidence of a judgement, has disappeared from analytical philosophy. Nelson, in his Über das sogenannte Erkenntnisproblem (1908), focuses on Meinong's use of the term 'evidence', and criticizes the idea that evidence may be used as a criterion to distinguish judgements that are knowledge from those that are not. Nelson argues in general that such a criterion cannot be given, which he calls the problem of the criterion, and that this problem also applies to the idea that evidence may function as criterion. He formulates 'the problem of evidence' in such a way that it can be conceived of as the standard criticism on the notion of evidence:

Either the concept of evidence entails the characteristic of truth, in which case it is impossible to decide whether a judgement is evident. Or 'evident' merely means an experience of consciousness that can psychologically be ascertained, in which case it is impossible to determine that an evident judgement is true. (Nelson 1908, p. 124)

I will argue that the notion of evidence as it is introduced in this paper differs in an important sense from the notion of evidence introduced by the early phenomenologists, and that Nelson's criticism therefore does not apply. The point is that the cognitive act that makes the judgement evident is essentially a cognitive act for me in the sense that the cognitive act counts as cognitive from a first-person point of view. Another person may look upon the act as not cognitive at all; this may effect the way I consider the act at a later moment, but only insofar as the other person is able to show me that I was wrong. The thesis that the cognitive act is cognitive from a first-person point of view has an important bearing on the notions of judgemental evidence and correctness: the evidence and the correctness of a judgement are fallible, and evidence and correctness mean evidence-for-me and truth-for-me. Later, the judgement may no longer count as 
evident, because the act on which the evidence of the judgement depends is no longer considered to be cognitive by the judger.

Both in Brentano and Husserl one finds the idea that something is true if it is possible to judge it with evidence: a conceptual relation between the notions evidence and truth is affirmed. In contrast to Husserl, Brentano does not acknowledge degrees of truth, and his theory seems therefore more apt for making a comparison with the theory as it is presented here. Besides, in the Prolegomena zur reinen Logik of the Logische Untersuchungen Husserl defines evidence in terms of truth, whereas Brentano defines (judgemental) truth in terms of evidence, just as this is done above. ${ }^{27} \mathrm{I}$ take Brentano's later theory as starting-point, in which only persons and things are acknowledged. According to Brentano, a judger's judgement is correct in the strict sense (right, richtig) precisely if the judger judges with evidence. And the right judgement is knowledge. ${ }^{28}$ The judgement of a judger may also be correct in a less strict, extended sense (true, wahr): truth belongs to the judgement of a judger who asserts what an evident judger would assert. ${ }^{29}$ The evident judger in this explanation of truth is to be understood as an ideal judger. For Brentano, the notion of ideal, evident judger is not a notion given in complete abstraction from actual, human judgers. According to Brentano, all knowing beings have the same proof grounds (Beweisgründe; Brentano 1930, p. 150), and, we are not entitled to assert anything about other beings having a different type of axiomatic knowledge (Brentano 1956, p. 171).

Brentano's explanation of truth in the extended sense corresponds to the idea of judgemental correctness introduced above: both notions are defined in terms of the possibility to make the judgement evident. There is also an important difference between the two truth notions. In Brentano, (judgemental) truth is explained in terms of the evident judgement of an ideal judger; the evident judgement is infallible: error is excluded. ${ }^{30}$ According to Brentano, if someone judges with evidence, the evidence transcends his judgement insofar as it corresponds, by definition, to the judgement of the ideal judger: truth and evidence are infallible. Brentano also says that if the judger's judgement is evident, he is certain of its truth, that is, the judgement's being evident is epistemically accessible to the judger. ${ }^{31}$ The judgement's being evident is thus conceived of as being both transcendent to the judger and phenomenologically

\footnotetext{
27 Cf. Husserl (1901, Prol., Sect. 51), where evidence is explained as experience of the truth ('Erlebnis' der Wahrheit).

28 Denn die Logik [...] soll uns das Verfahren lehren, das uns zu der Erkenntnis der Wahrheit führt, d.i. zum richtigen Urteil”" (Brentano 1956, pp. 1, 2).

29 “dass die Wahrheit dem Urteile des richtig Urteilenden zukommt, d.h. .... der das behauptet, was auch der evident Urteilende behaupten würde" (Brentano 1930, p. 139). The definition is from 1915. More on Brentano's theory of truth and evidence, and his distinction between truth in the strict sense and truth in the extended sense in van der Schaar (1999, 2003). In my (1999) paper it is shown that both Brentano and Martin-Löf defend a negative version of the law of excluded middle.

30 "Bei Evidenz ist Irrtum ausgeschlossen" (Brentano 1930, p. 144). In the sixth Logical Investigation (Sect. 39), Husserl says that if someone experiences the evidence of $A$, then it is evident that no one can experience the absurdity of the same A. In Formale und transzendentale Logik, published in 1929, Husserl has changed his position: evidence does no longer exclude the possibility of illusion or error (Täuschung, Husserl 1929, pp. 139, 140).

31 "Bei Evidenz ist Zweifel ausgeschlossen" (idem).
} 
accessible to him. Nelson's criticism thus applies to Brentano's theory: the thesis that evidence is transcendent in order to make evidence a guarantee of infallible truth is incompatible with the thesis that evidence is epistemically accessible to the judger, for the latter thesis implies that evidence is not a guarantee of infallible truth. The point is that one has to chose consistently for one side of Nelson's dilemma. In this paper, the judgement's being evident is understood as epistemically accessible to the judger; evidence is therefore understood as fallible evidence. This means that a judgement's being evident does not give a guarantee for infallible truth: error is not excluded.

Evidence obtains its fallibility from the cognitive act that makes the judgement evident. We trust our cognitive acts that bestow evidence upon our judgements. This does not imply that it does not make sense to doubt our cognitive act and the evidence of the judgement, but we should only do so when we have a reason for our doubt. The point is not that we have to explain why our cognitive acts make our judgements evident or justified, we simply take that for granted, and I take the two notions, that of cognitive act and that of the judgement's being evident, to be conceptually related. What we do need to explain is the possibility that our cognitive act might be an illusion.

\section{Truth and the possibility of error}

Regarding our going wrong, one should make a distinction between mistakes and errors. One may, for example, mistake one number, or one person, for another. As soon as someone shows that we mistook the one for the other, we know how to apprehend the right number or person. Such going wrong may be called a mistake. Truth and falsity are not necessarily involved in order to explain what a mistake is. Those who consider formal systems to be given prior to any meaning that can be given to them generally do not speak of the truth of the axioms and theorems of the system as such, but they acknowledge that mistakes can be made with respect to the system.

There is also a form of going wrong that cannot be understood independently of truth. Suppose that I assert that it is snowing, and I am entitled to make that assertion because I have seen that it is snowing by looking through the window. Some time later, I realize that I am in a movie-setting, and I doubt whether it was really snowing. I realize that I might be wrong with respect to my act of perception. Such going wrong would be an error: one takes an illusion to be real. If one defends the thesis that truth means nothing but truth-for-me, that is, if one defends a relativism regarding truth, one is able to account for illusions to a certain extent. In the example given above, one may say that given that I now have information that what I thought to be falling snow was perhaps not real snow, it is no longer true-for-me that it is snowing. If truth is nothing but truth-for-me, it is not possible, though, to say that something is true-for-me now, but that what is true-for-me now might not be true at all. Or, to extend the first-person perspective to the perspective of our culture, there is no way to say that something is true-for-us, but that we all might live in error. There is thus a fundamental form of illusion that cannot be explained if one defends a relativism with respect to truth.

If one defends the thesis that truth is nothing but truth-for-me, there is not a contradiction involved, if, on the presupposition that $A$ is a proposition, one person judges $A$ is true, and another judges $\neg A$ is true, for this would mean that, say, John judges 
that $A$ is true-for-him, while Mary judges that $A$ is true-for-her. The acknowledgement of the law of contradiction means that one denies a relativism regarding truth. Martin-Löf gives the following formulation of the law of contradiction: one and the same proposition cannot both be known to be true and be known to be false (Martin-Löf 1995, p. 194). To understand why this law holds, one has to go back to the meaning explanation of the proposition called absurdity. Absurdity is defined by its having no canonical proof object. It is thus impossible to know a proof of absurdity. This implies that it is impossible to know that absurdity is true. Martin-Löf thus arrives at one of the laws of knowability: Absurdity cannot be known to be true. In order to show that the law of contradiction holds we need both this law of knowability and the following rule of inference:

$\frac{A \text { true } A \text { false }}{\perp \text { true }}$

(N.B. $A$ is false is interderivable with $\neg A$ is true, Martin-Löf 1995, p. 192). If the judgements $A$ is true and $A$ is false were both knowable, then absurdity is true would be knowable. But, absurdity cannot be known to be true. Therefore, the two judgement candidates $A$ is true and $A$ is false cannot both be knowable, that is, they cannot both be correct. We are now entitled to say that if someone makes the judgement $A$ is true, whereas someone else asserts that $A$ is false (it may be the same person at different times), not both can be right. At least one of the cognitive acts on which these two judgements were based must have been an illusion.

From a philosophical point of view, this implies that there is more to truth than the evidence of the judgement. We are in need of a notion of truth that makes it possible to say: my judgement is evident to me, but it may be the case that the cognitive act on which the evidence of the judgement is based is an illusion. In order to be able to make the distinction between a real and an illusory cognitive act, another notion of truth is needed. Martin-Löf calls this notion of truth the metaphysical notion of truth, and he also speaks of truth as reality, truth as rightness (rectitudo), or truth as infallibility. If one identifies the epistemic notion of correctness with the metaphysical notion of truth, as Brentano did, one is confronted with Nelson's problem of the criterion. This leaves us two options. One may either explain the truth of a proposition in terms of the existence of a state of affairs, where the existence of the state of affairs is understood as truth as reality to which the proposition is said to correspond. This is the realist alternative. Or, one may understand truth as reality as pertaining to the cognitive act. Per Martin-Löf applies the notion of reality or rightness to the act, and in an epistemological context it applies to the cognitive act. "Is it that an act is right if the object of that act is right, or is it that an object is right if it has been rightly done? ... rightness applies primarily to the action and only derivatively to the object" (Martin-Löf 1991, p. 146). By understanding rightness primarily to pertain to the cognitive act, Martin-Löf commits himself to a variant of idealism. ${ }^{32}$

\footnotetext{
32 That is, a form of idealism one may also find in Peirce, who introduces the notion of metaphysical truth or reality in his paper 'How to Make Our Ideas Clear': "The opinion which is fated to be ultimately agreed to by all who investigate, is what we mean by the truth, and the object represented in this opinion is the real. That is the way I would explain reality" (Peirce, 1878, p. 139).
} 
Whether one's cognitive act is a 'real' one, is something we, being fallible creatures, are not able to determine. "[A]s a matter of fact, our demonstrations are not infallible: a demonstration purports to make something evident to us, and it is the best guarantee that we have, but it is not infallible" (Martin-Löf 1998, p. 110). According to MartinLöf, our concept of knowledge should not have the metaphysical notion of truth as part of its explanation, for that would make knowledge to be infallible and humanly inaccessible (Martin-Löf 1991, p. 144). If the metaphysical notion of truth were part of the explanation of knowledge, we would never be able to determine whether we know. Human knowledge is fallible in the sense that it does not exclude error; there is no guarantee that the cognitive act on which our knowledge is based, might not be an illusion. ${ }^{33}$

There is a danger in using the term 'real cognitive act': one should not understand it as denoting a special kind of cognitive act. 'Real' is not a characteristic that some cognitive acts have as opposed to others. There are not two types of cognitive act: the ordinary, prima facie one, and the real one. The term 'real' is not a determiner; it can only be made sense of when doubt is raised. Suppose someone wants to sell you a watch, which he asserts to be 'golden', for a small amount of money. Because of the price, you have reason to ask yourself: 'Is it real gold?' Only against the possibility of an illusion does the term 'real' make sense. According to Austin, "[ $\mathrm{t}]$ he doubt or question 'But is it a real one?' has always (must have) a special basis, there must be some 'reason for suggesting' that it isn't real" (Austin 1946, p. 87). Austin points to a contrast between standard terms and the term 'real'. In standard cases, the affirmative use of a term is basic: to understand ' $\mathrm{x}$ ', one needs to know what it is to be $\mathrm{x}$. "But with 'real'... it is the negative use that wears the trousers" (Austin 1962, p. 70). To understand the term 'real (gold)', one needs to know what it is for something not to be real (gold).

\section{An evaluation of the constructivist account of knowledge}

I focus on two questions that may be asked to evaluate a philosophical theory. Does it throw any light on the problems that philosophy is struggling with, today? And, do the philosophical notions of the theory suit our use of these notions in daily life? It is usually said that constructivism may be apt for mathematics, but that there is no use for constructivism outside of mathematics. Charles Parsons argues that the constructivist explanation of knowledge and truth cannot be extended to empirical knowledge, because: "In intuitionism, possession of a proof of $A$ guarantees the truth of $A$. But in most domains of knowledge even very strong evidence for a statement $A$ might be called in question by additional evidence" (Parsons 2004, p. 193).

\footnotetext{
33 Current epistemology explains the fallibility of knowledge in different terms: a subject's knowledge that $S$ is fallible in so far as the knowing subject is not able to eliminate the possibility of it being true that not $S$, given the (pieces of) evidence that person has for $S$ (cf. Lewis 1996, p. 549ff). This explanation of fallibility does not inherently effect all our judgements, as does the notion of fallibility used here. Martin-Löf's concept of fallible knowledge is closer to Peirce's, as Göran Sundholm pointed out to me. Peirce describes himself as a contrite fallibilist: there is no reason to suppose that any of our judgements might not involve error.
} 
I think, though, that the constructivist explanation of knowledge and truth can be used beyond mathematical knowledge. Above, knowledge is explained as a judgement made evident by a cognitive act. In the singular, empirical case the judgement is equally made evident by a cognitive act, namely an act of (judgemental) perception. For example, the judgement (candidate) there is a robin in my garden is made evident by an act of perception that there is a robin in my garden. Parsons is right that the act of perception may be called in question: if we know more about the situation, we may consider the act of 'perception' not to be cognitive: the perceptual act is no guarantee for the infallible truth of the judgement. This cognitive act does nevertheless make the judgement evident. ${ }^{34}$ The point is that there is in this respect no difference between an act of perception and an act of insight or an act of demonstration, the relevant cognitive acts within mathematics. The act of demonstration that makes a judgement candidate into a theorem might not be a real 'act of demonstration'; the theorem is fallible knowledge. Parsons is not right insofar as he claims that within mathematics possession of a proof of $A$ guarantees the (infallible) truth of $A$. Of course, there are important differences between the cognitive acts inside mathematics and logic and those outside these fields, but these differences do not constitute a difference in the explanation of knowledge and truth.

The concept of knowledge as state that is introduced in this paper may be generalized beyond mathematics and logic. This means that (propositional) knowledge as state is understood as the result of a cognitive act. One need not remember the first cognitive act; the role of memory can be restricted in the way it is done by Locke. My reconstruction of Locke's definition of habitual knowledge can be used, with some changes, to give an explanation of knowledge as state in general.

$P$ has knowledge that $S$, precisely if:

- $P$ has once had the cognitive act that $S$;

- The cognitive act that $S$ is stored in the memory of $P$, such that: whenever $P$ apprehends the judgement candidate $S$, he judges that $S$.

One of the advantages of this explanation of knowledge is that it does not make use of the ambiguous notion of belief (see the end of Sect. 2). Another advantage is that Gettier cases do not arise on this account (see below).

Do we use in daily life a fallible notion of knowledge as explained in Sects. 5 and $6 ?$ Austin asserts in his paper 'Other Minds' that our ordinary concept of knowledge is that of fallible knowledge: "we are often right to say we know even in cases where we turn out subsequently to have been mistaken - and indeed we seem always, or practically always, liable to be mistaken... The human intellect and senses are, indeed, inherently fallible and delusive, but not by any means inveterately so" (Austin 1946, p. 98). Our daily concept of knowledge does not involve infallibility; it so often has happened that what was called 'knowledge', no longer is considered to be knowledge. Why should we think that this will not happen to what is today called 'knowledge'? This does not imply that we continually have to speak about what we consider to be knowledge; it is simply what we call knowledge. In possession of the relevant stud-book papers,

$\overline{34 \text { Not infallibly evident, of course. }}$ 
you know that your stallion is Arabian. Because knowledge implies (epistemic) truth, it follows that it is true that the horse is a thorough-bred. If you cannot provide any documents that prove that it is a thorough-bred, I might doubt whether you know it, and, most likely, I will doubt whether it is true at all. Austin understands knowledge not in terms of knowledge attributions, but in terms of assertions of the form 'I know that $S$ ', which he does not conceive as special cases of knowledge attribution. To do so would be an example of the descriptive fallacy (Austin 1946, p. 103). "It is naturally always possible ('humanly' possible) that I may be mistaken ..., but that by itself is no bar against using the expression(s) 'I know' ... as we do in fact use [it]" (Austin 1946, p. 98). Austin thus defends the thesis, as I have done in this paper, that knowledge is what counts as knowledge from a first-person perspective.

A topic that applies both to the question whether the knowledge concept defended here is apt for daily life, and to the question whether the constructivist concept of knowledge may throw light on the problems that philosophy is struggling with, is that of assertion. Several philosophers have defended a knowledge account of assertion, and this account suits constructivism, because judgement and its linguistic counterpart assertion are explained in terms of what one has to know in order to be entitled to make the relevant judgement or assertion. According to Timothy Williamson, the rule of assertion is that "One must: assert $p$ only if one knows $p$ " (Williamson 2000, p. 243). Bernard Williams has made a point against the knowledge account of assertion: knowledge is too strong a demand ('norm') for assertion. According to Williams, the speaker "may not be in the position himself to apply the norm effectively, because, at the point of asserting that $\mathrm{P}$, he may reasonably think that he knows that $\mathrm{P}$ when he does not" (Williams 2002, p. 76). This criticism is applicable to those knowledge accounts of assertion that take knowledge that $S$ to imply the infallible truth of $S$. How could we ever meet a demand of infallible truth? Since one never knows whether $P$ is really true, the above-mentioned rule of assertion transcends the game and the players alike. If one defends a knowledge account of assertion, and understands that knowledge is always knowledge from a first-person perspective, the criticism does not apply. On the account of knowledge defended in this paper, the rule that 'One is entitled to assert that $S$ only if one knows that $S$ ' demands of the asserter that he has perceived or demonstrated that $S$, but not that $S$ is 'really', infallibly true. The point is that the knowledge claimed in assertion is what counts as knowledge from a first-person perspective.

The constructivist concept of knowledge may be used to clarify two other problems in modern epistemology: the problem of skepticism, especially as it is dealt with by contextualism, and the Gettier problem. Austin's paper 'Other Minds', already mentioned above, is presented as an answer to skeptical problems relating to other minds. According to Austin, fallibility is essential to knowledge: "It is futile to embark on a 'theory of knowledge' which denies this liability: such theories constantly end up by admitting the liability after all, and denying the existence of "knowledge"' (Austin 1946, p. 98). One of the causes of skepticism is that philosophers have explained knowledge in terms of metaphysical or infallible truth. Because we are never able to determine whether our judgement is really, infallibly true, knowledge is impossible to determine on such an account. The modern answer to skepticism is contextualism: "Contextualists hold that the truth conditions of knowledge-ascribing and 
knowledge-denying sentences ... fluctuate in certain ways according to the context in which they are uttered" (DeRose 2002, p. 168). According to contextualists, standards of justification vary relative to context. In most contexts, when we have reasonable evidence, our standards of justification are such that we do have knowledge according to those standards. In other contexts, especially that of the skeptical philosopher, standards are raised, they say, so that we do not have knowledge, although we are in possession of the same evidence as before. I think, though, that contextualism grants the skeptic too much. One should answer the skeptic in the Austinian manner: do not doubt, when there is no reason to doubt.

According to Edmund Gettier and modern epistemology, the standard explanation of knowledge as justified true belief is problematic, because we can imagine cases, so-called Gettier cases, in which there is justified true belief without knowledge. I start with a simple Gettier case, Alvin Goldman's description of a man perceiving a barn in barn facade county in Goldman (1976). Henry is driving along the road, sees a barn, and says to his young son 'That is a barn'. In standard cases, we say that Henry knows that it is a barn. The Gettier case is created by adding extra information of which Henry has no knowledge. Henry happens to drive in a district that is full of papier-mache facsimiles of barns. They look like barns, but are incapable of being used as such; they have no back walls or interiors. By accident, the object that Henry takes to be a barn, is a real barn, not a barn facade, but, because it is merely by accident that he has hit upon a real barn, we seem to be reluctant to say that Henry knows that there is a barn. His belief that this is a barn is justified and true, but it seems not to be knowledge, because his belief seems to be the result of pure luck.

The standard reaction to Gettier cases has been that the believer's justification should not depend on pure luck. It also has been suggested, though, that Gettier cases can be formulated only when one tries to make a wedge between the notions being justified and being true. Already in 1974, Robert Almeder asks the question: "if the satisfaction of the evidence condition does not entail the satisfaction of the truth condition, then how could the truth condition be satisfied at all?" (Almeder 1974, p. 367). On the explanation of knowledge given here, in which the cognitive act on which one's knowledge is based is understood to be a cognitive act from a first-person perspective, Gettier cases cannot consistently be formulated. The judgement that this is a barn is justified by Henry's act of perception that this is a barn; he therefore knows that this is a barn. As long as he has no knowledge of barn facades, he is fully entitled to make the assertion that this is a barn, because he has no reason to doubt his perception; his perception counts as cognitive from his point of view. From the point of view of the attributor of knowledge, who has his own first-person perspective, and who knows about all the barn facades, Henry's judgement does not count as justified, because he is not able to discriminate this case from the fake cases. From the attributor's point of view, Henry does not have knowledge, but neither does he have a justification for his assertion. The moment Henry realizes that he is driving in barn facade county, he raises doubts concerning his act of perception, for he understands now that he cannot distinguish a barn from a barn facade. Given his new first-person perspective, he no longer considers himself to be knowing that this is a barn, and he considers his act of 
perception not to be cognitive in the sense that it makes the judgement that this is a bar justified.

The second case in Gettier (1963) is the one where Smith judges that either Jones owns a Ford, or Brown is in Barcelona. Smith knows that Jones always had a Ford, and Jones just offered him a ride while driving a Ford, so he seems to be justified in his judgement that Jones owns a Ford. On the basis of the judgement that Jones owns a Ford, he infers the disjunction that Jones owns a Ford, or Brown is in Barcelona. Smith does not know that Brown is in Barcelona, but he is justified in the disjunctive judgement, because the judgement that Jones owns a Ford is justified. I am not sure that Smith's judgement that Jones owns a Ford is justified, but let us suppose that it is. This means, on the account of knowledge in this paper, that he knows that Jones owns a Ford, and he therefore knows the disjunctive judgement as soon as he has made the inference step. The Gettier case is formulated as follows. Unknown to Smith, Jones does not own a Ford, but Brown is in Barcelona. This would mean that Smith's belief in the disjunction is justified, because of the evidence he has concerning Jones, and true, because Brown is in fact in Barcelona. On a constructive account, in order for Smith to have knowledge that Jones owns a Ford, or Brown is in Barcelona, at least one of the two disjuncts needs to be justified, which makes this disjunct correct. From Smith's, that is, the subject's, point of view, his judgement that Jones owns a Ford is justified, and he therefore knows the disjunction, as soon as he made the inference step. Whether we, who attribute knowledge or mere belief to the subject, consider Smith's judgement to be justified, depends on our point of view, and all the extra information we have obtained about Smith, Jones and Brown. Given that we know that Jones does not own a Ford, we do not count Smith's 'evidence' for the judgement that Jones owns a Ford as giving him a justification for his judgement. Smith has therefore no justification for the disjunctive judgement, and thus has no knowledge, from the perspective of an attributor who has all the background information. The only thing we can say is that not both the subject and the knowledge attributor can be right.

In order to formulate a Gettier case one has to shift, in the same story, from the perspective of the subject, in order to call his belief 'justified', to that of the attributor, who knows that the subject's belief is true, for a completely different, accidental reason. Essential to the thesis that knowledge is what counts as knowledge from a first-person perspective, is that we always make our claims from a certain perspective, and that one cannot adopt two perspectives at the same time. Given that knowledge is essentially first-person, that is, that knowledge is perspectival, Gettier cases cannot be formulated. The intuition that underlies the Gettier problem is the constructivist point that even though a judgement is evident, it is fallible: the cognitive act on which the evidence of the judgement depends, might not be a 'real' cognitive act.

\section{Conclusion}

The notion of cognitive act is of importance for an epistemology that is apt for constructive type theory, and for epistemology in general. Linguistic philosophers, such as Zeno Vendler, have pointed out that there are certain uses of the verb 'to know' that indicate that we have such a concept. It is argued here that an epistemology for 
constructive type theory needs to explain its epistemic concepts in terms of the primitive notion of cognitive act. Instead of taking knowledge attributions as the primary use of the verb 'to know' that needs to be given an account of, and understanding a first-person knowledge claim as a special case of knowledge attribution, the account of knowledge that is given here understands first-person knowledge claims as the primary use of the verb 'to know'. Knowledge attributions are understood as a complex and derived phenomenon. It is for this reason that one may call the concept of knowledge explained in this paper a phenomenological concept of knowledge.

There are also important differences between the notion of knowledge introduced here and that of the early phenomenologists: an epistemology for constructive type theory is not in need of a separate act of intuition, besides the cognitive act, in the elucidation of the different moments that are presupposed by the cognitive act. The notion of judgemental evidence as it is introduced here also differs from the notion of evidence used by the early phenomenologists: evidence as it is understood in this paper is fallible, because the evidence of a judgement is the result of a cognitive act, that is, an act that counts as cognitive for the person who makes the judgement. This means that the problem of evidence formulated by Nelson can be answered: evidence is to be understood as a phenomenological characteristic of our judgements, not as a characteristic that transcends the judging person.

A judgement is evident if it is the result of a cognitive act that counts as cognitive for the judging person. This means that being evident is being evident-for-me, and because epistemic truth, or judgemental correctness, is explained in terms of evidence, this seems to imply a relativism with respect to truth, and it thus seems that there is a form of error that cannot be explained by the theory. It is for this reason that another notion of truth is introduced, truth as reality.

The order of explanation of the epistemic concepts in this paper is different from the explanatory order in modern analytic epistemology, where knowledge is explained in terms of belief, and this makes the theory sometimes difficult to understand. The cognitive act is understood here as a primitive notion, and the act of judgement is explained in terms of the cognitive act. A mere act of judgement, judging without a ground, is understood as a modification of the cognitive act. The way such concepts as modification and etiolation are used in this paper, and the idea that we need to explain first-person knowledge claims prior to giving an explanation of knowledge attributions are part of a method that may be called linguistic phenomenology.

If one takes seriously the idea that knowledge is primarily knowledge from a firstperson perspective, Gettier cases cannot consistently be formulated. Gettier cases can only be formulated if one shifts within the same story from the perspective of the knowing subject, from which perspective the judgement counts as justified and correct, and thus as knowledge, to the perspective of the person who is to attribute knowledge to the subject, from whose perspective the 'justification' and 'truth' of the judgement are the result of pure luck, which means that the subject is not considered to have knowledge. It thus seems to be possible to use the concept of knowledge introduced in this paper to elucidate certain problems in modern epistemology.

Acknowledgements I thank Per Martin-Löf and Göran Sundholm for extensive comments on a former version of this paper. I thank Mark van Atten for the stimulating discussions on intuitionism and 
phenomenology during my sabbatical leave in Paris (IHPST, fall 2005), and my colleague Eric Schliesser for his comments on a former version of this paper. Parts of this paper were presented at Groningen, Paris (IHPST), Leuven and Aberdeen; I thank the organizers and participants.

Open Access This article is distributed under the terms of the Creative Commons Attribution Noncommercial License which permits any noncommercial use, distribution, and reproduction in any medium, provided the original author(s) and source are credited.

\section{References}

Adler, J. E. (2002). Belief's own ethics. Cambridge, MA: MIT Press.

Almeder, R. (1974). Truth and evidence. The Philosophical Quarterly, 24, 365-368.

Austin, J. L. (1946). Other minds. In J. L. Austin (Ed.), Philosophical papers (2nd ed., pp. 76-116). Oxford: Oxford University Press. (Reprinted in 1970)

Austin, L. J. (1962). Sense and sensibilia. Oxford: Oxford University Press.

Bernet, R., Kern, I., \& Marbach, E. (1989). Edmund Husserl: Darstellung seines Denkens. Hamburg: Felix Meiner Verlag.

Brentano, F. (1930). Wahrheit und Evidenz. Hamburg: Felix Meiner Verlag.

Brentano, F. (1956). Die Lehre vom richtigen Urteil. Bern: Francke Verlag.

DeRose, K. (2002). Assertion, knowledge, and context. The Philosophical Review, 111, 167-203.

Gettier, E. (1963). Is justified true belief knowledge?. Analysis, 23, 121-123.

Goldman, A. (1976). Discrimination and perceptual knowledge. The Journal of Philosophy, 73, 771-791.

Hamlyn, D. W. (1968). Aristotle De Anima. Translated with Introduction and Notes by D. W. Hamlyn. Oxford: Clarendon Press. (Reprinted in 1993)

Heyting, A. (1931). Die intuitionistische Grundlegung der Mathematik. Erkenntnis, 2, 106-115.

Husserl, E. (1901). Logische Untersuchungen, Hua XVIII, E. Holenstein (Ed.). (The Hague: Martinus Nijhoff, 1975); and Hua XIX, U. Panzer (Ed.). (The Hague: Martinus Nijhoff, 1984).

Husserl, E. (1929). Formale und transzendentale Logik; Versuch einer Kritik der logischen Vernunft. Halle: Max Niemeyer Verlag.

Husserl, E. (1939). Erfahrung und Urteil. Hamburg: Felix Meiner Verlag. (Reprinted in 1985)

Lewis, D. (1996). Elusive knowledge. Australasian Journal of Philosophy, 74, 549-567.

Locke, J. (1689). In P. H. Nidditch (Ed.), An essay concerning human understanding (based on the fourth edition). Oxford: Clarendon Press. (Reprinted in 1975)

Martin-Löf, P. (1985). On the meanings of the logical constants and the justification of the logical laws. Nordic Journal of Philosophical Logic, 1, 11-61. http://www.hf.uio.no/filosofi/njpl. (Reprinted in 1996)

Martin-Löf, P. (1987). Truth of a proposition, evidence of a judgement validity of a proof. Synthese, 73, 407-420.

Martin-Löf, P. (1991). A path from logic to metaphysics. In Atti del Congresso Nuovi problemi della logica e della filosofia della scienza (Vol. II, pp. 141-149). Bologna: CLUEB.

Martin-Löf, P. (1995). Verificationism then and now. In W. Schlimanovich, E. de Pauli, \& F. Stadler (Eds.), The foundational debate (pp. 187-196). Dordrecht: Kluwer.

Martin-Löf, P. (1998). Truth and knowability: On the principles C and K of Michael Dummett. In H. G. Dales \& G. Oliveri (Eds.), Truth in mathematics (pp. 105-114). Oxford: Clarendon Press.

Moser, P. K. (1989). Knowledge and evidence. Cambridge: Cambridge University Press.

Nelson, L. (1908). Über das sogenannte Erkenntnisproblem. In Paul Bernays, a.o. (Eds.), Leonard Nelson Gesammelte Schriften II. Hamburg: Felix Meiner. (Reprinted in 1973)

Parsons, C. (2004). Brentano on judgment and truth. In D. Jacquette (Ed.), The Cambridge companian to Brentano (pp. 168-196). Cambridge: Cambridge University Press.

Peirce, C. (1878). How to make our ideas clear. In N. Houser \& C. Kloesel (Eds.), The essential Peirce (Vol. 1, pp. 124-141). Bloomington: Indiana University Press.

Ranta, A. (1994). Type-theoretical grammar. Oxford: Clarendon Press.

Ryle, G. (1949). The concept of mind. London: Hutchinson.

Sundholm, G. (1983). Constructions, proofs and the meaning of logical constants. Journal of Philosophical Logic, 12, 151-172. 
Sundholm, G. (1994). Existence, proof and truth-making: A perspective on the intuitionistic conception of truth. Topoi, 13, 117-126.

Sundholm, G. (1997). Implicit epistemic aspects of constructive logic. Journal of Logic, Language, and Information, 6, 191-212.

Sundholm, G. (1998). Inference, consequence, implication: A constructivist's perspective. Philosophia Mathematica, 6, 178-194.

Sundholm, G. (2002). A century of inference: 1847-1936. In P. Gärdenfors, J. Wolenski, \& K. Kijania-Placek (Eds.), In the scope of logic methodology and philosophy of science (Vol. II, pp. 565-580). Dordrecht: Kluwer.

Sundholm, G. (2004). Antirealism and the roles of truth. In I. Niniluoto, M. Sintonen, \& J. Wolenski (Eds.), Handbook of epistemology (pp. 437-466). Dordrecht: Kluwer.

Tugendhat, E. (1970). Der Wahrheitsbegriff bei Husserl und Heidegger. Berlin: de Gruyter.

van der Schaar, M. (1999). Brentano on truth and the law of excluded middle. In T. Childers (Ed.), The LOGICA yearbook 1998 (pp. 110-120). Prague: Filosofia.

van der Schaar, M. (2003). Brentano on logic, truth and evidence. Brentano Studien, 10, 119-150.

van der Schaar, M. (2006). On the ambiguities of the term Judgement. An evaluation of Twardowski's distinction betweeen action and product. In A. Chrudzimski \& D. Lukasiewicz (Eds.), Actions products and things; Brentano and Polish philosophy (pp. 35-53). Frankfurt: Ontos Verlag.

van der Schaar, M. (2007). The assertion-candidate and the meaning of mood. Synthese, 159, 61-82.

van der Schaar, M. (2009). Judgement, belief and accepance. In G. Primiero \& S. Rahman (Eds.), Acts of knowledge: History, philosophy and logic; essays dedicated to Göran Sundholm (pp. 267286). London: College Publications.

Vendler, Z. (1967). Linguistics in philosophy. Ithaca: Cornell University Press.

von Kutschera, F. (1981). Grundfragen der Erkenntnistheorie. Berlin: de Gruyter.

Williams, B. (2002). Truth and truthfulness. Princeton: Princeton University Press.

Williamson, T. (2000). Knowledge and its limits. Oxford: Clarendon Press. 